\title{
International Banking and Cross-Border Effects of Regulation: Lessons from Hong Kong*
}

\author{
Kelvin Ho, Eric Wong, and Edward Tan \\ Hong Kong Monetary Authority
}

Using a confidential data set of foreign bank affiliates (FBAs) in Hong Kong, this study finds evidence of an international transmission of prudential policies through banks' balance sheets from a host-country perspective. Specifically, in response to tighter capital requirements in the home country, parent banks with a higher tier 1 capital ratio tend to sustain higher loan growth by their FBAs in Hong Kong than their peers. When tighter liquidity requirements are considered, differences in parent banks' core deposit shares and reliance on net intragroup funding are found to significantly affect the loan responses of FBAs in Hong Kong. One implication is that from a host supervisor's perspective, understanding the balance sheet structure of an FBA's parent bank is important in assessing the international transmission of prudential policies. Regarding the impact on the loan supply of the Hong Kong banking sector, our findings show that the size of the spillover effects for the overall capital requirements and reserve requirements are larger than those for sector-specific prudential measures. The relatively smaller spillover effects for sector-specific prudential measures can be partly explained by a significant portfolio rebalancing effect both across and within affiliates of international banks, making the net impact on the host country less clear.

JEL Codes: E58, F34, G21, G28.

${ }^{*}$ Author contact (all authors): Research Department, Hong Kong Monetary Authority, 55/F, Two International Finance Centre, 8 Finance Street, Central, Hong Kong, China. Ho: Tel: +852 2878 1794; Fax: +852 2878 1891; E-mail: kkwho@hkma.gov.hk. Wong: Tel: +852 2878 8735; Fax: +852 2878 1891; E-mail: etcwong@hkma.gov.hk. Tan: Tel: +852 2878 1734; Fax: +852 2878 1891; E-mail: ekytan@hkma.gov.hk. 


\section{Introduction}

While prudential policies have been increasingly tightened by policymakers globally to contain systemic risk after the global financial crisis (figure 1), their implementation may have unintended international spillover effects. The issue of international spillovers of prudential policies has drawn increasing attention from policymakers. Hong Kong is an international financial center with a strong presence of foreign banks, implying that the Hong Kong banking sector is not immune to the spillover effects arising in the home countries of foreign affiliate banks in Hong Kong.

To broaden our understanding of this policy issue, this paper focuses on the cross-border inward spillover effects of prudential policies from a host-country perspective. More specifically, we examine how foreign banks' affiliates (FBAs) 1 in Hong Kong adjust their lending in response to tighter prudential policies imposed in their home countries.

The strong presence of FBAs in Hong Kong provides a natural and suitable experiment setting to study the issue of inward spillover effects of prudential policies from the home countries of foreign banks. At the end of 2014, there were 191 FBAs operating in Hong Kong, accounting for 73 percent of total banking assets 2 Although these FBAs operate with different business functions, in aggregate they account for 74 percent of total banking-sector loans. Since these FBAs are subject to prudential policies imposed in their home countries $(H o m e P)$, by studying how their change in lending in Hong Kong is associated with changes in HomeP, we can identify the inward spillover effects of HomeP empirically. The large number of foreign banks in Hong Kong is conducive to a reliable statistical result. Meanwhile, the inward spillover of foreign prudential measures could also arise through domestic banks' exposure of their affiliates in foreign markets, which, in turn, affects their lending behavior in Hong Kong. However, the identification of spillover effects for this specification is not feasible, as there are only a few domestic banks in Hong Kong that have operations in many foreign countries, and is therefore not examined in this study.

\footnotetext{
${ }^{1}$ This includes foreign bank branches and subsidiaries in Hong Kong.

${ }^{2}$ Of the total 191 FBAs in Hong Kong, 145 are foreign bank branches and 46 are foreign subsidiaries.
} 


\section{Figure 1. Average Cumulative Prudential Index of Advanced and Emerging Market Economies}

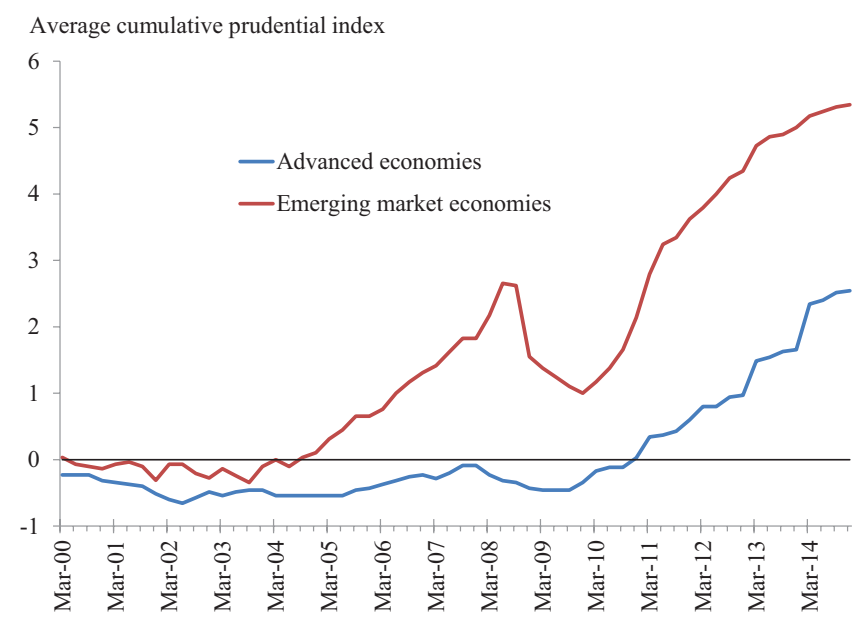

Source: Authors' estimates based on IBRN Prudential Instruments Database described by Cerutti et al. (2017).

Notes: The index reflects the average cumulative number of prudential policy actions by assigning a positive value for tightening and a negative value for loosening. Policy instruments include general capital requirements, sectorspecific capital requirements, limits on interbank exposure, concentration ratio limits, caps on loan-to-value ratios, and reserve requirements on local and foreign currencies.

We conduct our empirical study using a confidential panel data set reported by foreign banks to the Hong Kong Monetary Authority (HKMA) from 2000:Q1 to 2014:Q4, with parent-bank data obtained from Bankscope. Data on prudential policies are from the International Banking Research Network (IBRN) Prudential Instruments Database (Cerutti et al. 2017). All empirical estimations are based on the baseline analytical framework described in Buch and Goldberg (2017).

This study aims to answer two questions: First, do balance sheet characteristics matter for the inward transmission of prudential measures through FBAs' operations in Hong Kong? This question is particularly relevant to host-country policymakers, as international banks generally have very different balance sheet structures due to 
their heterogeneous business models 3 Second, do banks respond differently to alternative types of prudential measures and what is the economic magnitude of their response? We answer the second question by studying the directional changes of lending among FBAs in Hong Kong in response to various types of prudential measures and their aggregate impact on the banking sector's lending.

For the first question, we identify a set of bank balance sheet characteristics that could significantly affect the inward spillover effects of four types of prudential policies considered in this paper. We find that these bank balance sheet characteristics vary across prudential measures but are strongly associated with the nature of the prudential measure (i.e., capital or liquidity related) being studied. Specifically, we find that in response to tighter capital requirements in the home country, a bank with a higher tier 1 capital ratio tends to sustain higher loan growth of its affiliates in Hong Kong than that of other FBAs in Hong Kong. For tighter liquidity prudential measures (e.g., higher reserve requirements), a bank's core deposit share and its reliance on net intragroup funding are found to significantly affect the loan response of its affiliates in Hong Kong. Overall, these findings may reflect the notion that the loan response of FBAs in Hong Kong to tighter prudential measures in the home country is crucially dependent on how the tighter requirements produce a binding constraint on the capital or liquidity ratios of its banking organization.

For the second question, among the four types of prudential measure considered, only the overall capital requirements are estimated to have a clear pattern of spillover effects: most FBAs in the sample are estimated to reduce their lending in Hong Kong in response to tighter overall capital requirements in their respective home country. Consistent with this finding, the size of the spillover effects for the overall capital requirements is found to be larger than the size of those associated with sector-specific prudential measures. We attribute the latter finding to a significant portfolio rebalancing effect of FBAs in Hong Kong.

\footnotetext{
${ }^{3}$ Recent studies on international banking have found empirical evidence to support the idea that the balance sheet characteristics of global banks matter for the international transmission of risk. See Cetorelli and Goldberg (2012a, 2012b) and Buch and Goldberg (2014).
} 
The remainder of this paper is organized as follows. Section 2 provides a brief description of data and stylized facts for foreign affiliates in Hong Kong. Section 3 discusses the empirical models and results. Section 4 concludes.

\section{Data and Stylized Facts for Foreign Affiliates in Hong Kong}

\subsection{Bank-Level Data}

We construct affiliate-level variables for foreign banks in Hong Kong using regulatory data from the return of assets and liabilities and the quarterly analysis of loans and advances and provisions submitted to the HKMA. Parent-level variables are constructed using consolidated data of the ultimate parent from Bankscope 4 Details of the variables are shown in appendix 1 of Ho, Wong, and Tan (2016).

\subsubsection{Dependent Variable 5}

This empirical study includes the quarterly change in log total loans $\left(\Delta\right.$ Loans $\left._{b, j, t}\right)$ in the baseline estimation. In addition, changes in log mortgage loans $\left(\Delta\right.$ Mortgage $\left._{b, j, t}\right)$, corporate loans $\left(\Delta \operatorname{Corp}_{b, j, t}\right)$, and consumer loan: $6\left(\Delta\right.$ Consumer $\left._{b, j, t}\right)$ are analyzed to complement our investigation on whether foreign banks have an incentive to rebalance their loan portfolios in response to a tightening in prudential measures.

\subsubsection{Balance Sheet Characteristics}

We follow Cornett et al. (2011) in assuming that the ex ante balance sheet condition of a bank matters for the transmission of regulatory spillover effects. The ex ante balance sheet condition of a banking

\footnotetext{
${ }^{4}$ Since quarterly data are only available in recent years for most of our sample, missing quarterly data in the early part of the estimation period are obtained by linearly interpolating the annual data.

${ }^{5}$ All dependent variables considered are winsorized at the 1st and 99th percentiles. Apart from winsorizing the dependent variables, a robustness check has been conducted by excluding the log changes of loans exceeding 100 percent and -100 percent; the results remain broadly unchanged.

${ }^{6}$ This is defined as household loans excluding mortgage loans.
} 
organization is proxied by three parent-level variables: the fraction of the parent bank's assets that are illiquid at the beginning of period (IlliquidAssetsRatiob,j,t-1), the fraction of the parent bank's balance sheet financed with core deposits (CoreDeposits $s_{b, j, t-1}$ ), and the parent bank's regulatory tier 1 capital ratio (Tier 1 Ratio $_{b, j,-1}$ ). All specifications include the log of real total assets of the parent bank as a control variable (LogRealAssets $\left.s_{b, j-1}\right)$. In addition, we also include a ratio of NetDueTo to liabilities (NetDueTob,j,t-1) in the regression equation, where NetDueTo is defined as "due to overseas offices" (i.e., liabilities of foreign affiliates in Hong Kong) minus "due from overseas offices" (i.e., assets of foreign affiliates in Hong Kong), to capture an FBA's net intragroup funding. By definition, a positive (negative) NetDueTo for an FBA in Hong Kong means the FBA is a net borrower from (lender to) the rest of its banking group. An FBA with a large positive NetDueTo suggests that the FBA is more reliant on its parent bank's funding.

\subsection{Data on Prudential Instruments}

Regarding data on prudential instruments $\left(H o m e P_{j, t}\right)$, this study considers four types of policy instruments, which differ in scope of application and policy objectives. The first two are related to a bank's capital adequacy: the overall capital requirements $\left(\right.$ CapitalReg $\left._{j, t}\right)$ and sector-specific capital buffers $\left(S S C B_{j, t}\right)$, with the latter generally imposed on loans to the real estate sector. These two measures are usually applied on a consolidated basis at the parent-bank level. The loan-to-value ratio cap for mortgage loans $\left(L T V C a p_{j, t}\right)$, which is conventionally applied in a geographically confined area (e.g. mortgage loans in the home country), is also considered in this study. In addition, reserve requirements on localcurrency deposits $\left(R R\right.$ Local $\left._{j, t}\right)$, a measure affecting banks' liquidity is included in the analysis 7 The variable $H o m e P_{j, t}$ considered in the study is defined in the following fashion: 1 if country $j$ tightens

\footnotetext{
${ }^{7}$ Sector-specific capital buffers for consumer and other loans, the reserve requirements on foreign-currency deposits, interbank exposure limits, and concentration limits are excluded in estimation, as there is too little variation in these instruments in our sample (see table 2).
} 
a particular measure at time $t,-1$ if a country loosens the measure, and 0 otherwise 8

Furthermore, a prudential index $\left(\operatorname{Pruc}_{j, t}\right)$, which measures the aggregate prudential policy stance in the home country, is included in the estimation. The index is defined as being equal to 1 if the sum of all instrument indexes is greater than or equal to 1 at time $t,-1$ if that same sum is less than or equal to -1 , and 0 otherwise.

The estimation sample includes seventy foreign banks in Hong Kong, covering the period 2000:Q1-2014:Q4. These banks are selected using the following criteria: We first include all licensed banks with their parent bank's home country not equal to Hong Kong (i.e., the estimation sample includes both foreign bank branches and subsidiaries). We then exclude banks that are no longer active at the end of 2014 and have less than seven years of operation 9 Banks that have experienced mergers and acquisitions or changes in their home country or no lending operation during the sample period are also excluded. The estimation sample of banks accounts for about 79 percent of the total assets of all foreign banks in Hong Kong at the end of 2014.

\subsection{Stylized Facts}

The summary statistics for major variables in our estimations are shown in table 1 . There is a significant variation in the balance sheet structure among FBAs' parent banks, as reflected in a relatively large standard deviation for the tier 1 ratio, illiquid assets ratio, and core deposits ratio. This feature is consistent with the fact that international banks generally have very different balance sheet structures due to their diverse range of business functions. Similarly, the business functions of FBAs also exhibit a large degree of heterogeneity, as indicated by a large standard deviation for NetDueTo (i.e., 32 percent). The large standard deviation indicates that some FBAs in Hong Kong are highly reliant on net intragroup funding,

\footnotetext{
${ }^{8}$ For reserve requirements, changes in a given period $t$ could take a value of greater (lower) than $1(-1)$ to account for the intensity of the change in the instrument that the index captures.

${ }^{9}$ Thus, the selected FBAs have lending operations that cover at least half of the estimation period.
} 


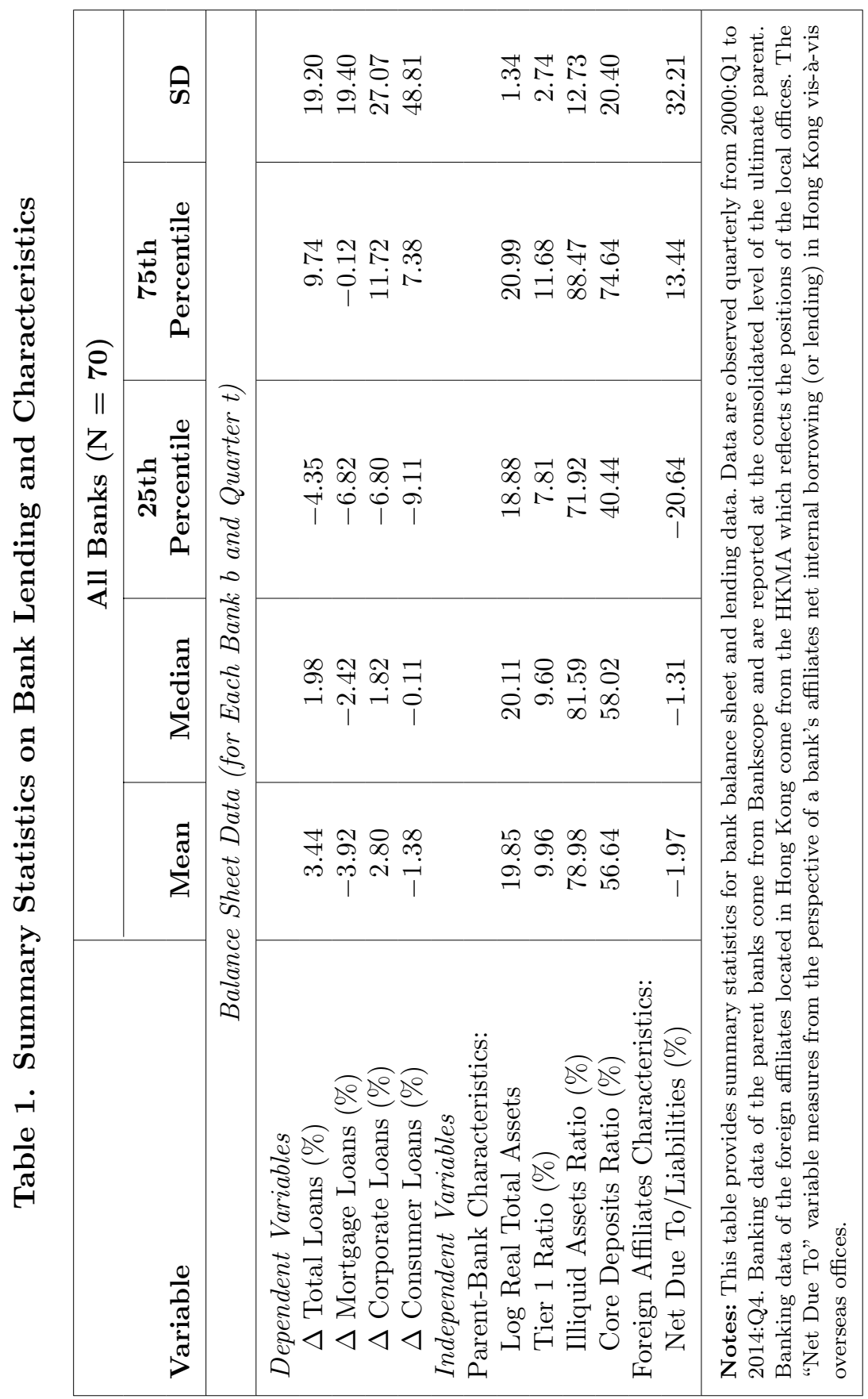


while some FBAs would instead act as net lenders to their banking organization.

Table 2 presents summary statistics on changes in the regulation in the home countries of the FBAs in our sample. The home countries of FBAs in our sample include twenty-one countries 10 of which six are emerging Asian economies and the rest are advanced economies. In general, the set of prudential instruments being implemented in each country tends to vary, and largely depends on country-specific conditions. Specifically, among the prudential measures being considered, overall capital requirements are the most widely adopted instruments, with all countries having tightened the requirements at least once over the estimation period. On the other hand, interbank exposure limits and concentration limits are the least-adopted instruments, with only a few countries implementing these types of instrument in our sample.

\section{Empirical Method and Regression Results}

\subsection{Baseline Analysis of Inward Transmission of Prudential Policies via Foreign Affiliates}

This section draws mainly on the framework developed by Buch and Goldberg (2017) to examine the inward spillover effects of prudential policies implemented abroad on Hong Kong via foreign bank affiliates. The empirical model is specified as follow:11:

$$
\begin{aligned}
\Delta Y_{b, j, t}= & \alpha_{0}\left(\alpha_{1} \text {HomeP }_{j, t}+\alpha_{2} \text { HomeP }_{j, t-1}+\alpha_{3} \text { HomeP }_{j, t-2}\right) \\
& +\alpha_{4} X_{b, j, t-1}+\alpha_{5} Z_{j, t} \\
& +\left(\beta_{1} \text {HomeP }_{j, t}+\beta_{2} \text {HomeP }_{j, t-1}+\beta_{3} \text {HomeP }_{j, t-2}\right) \\
& \cdot X_{b, j, t-1}+f_{b}+f_{t}+\varepsilon_{b, j, t}
\end{aligned}
$$

\footnotetext{
${ }^{10}$ These include Australia, Austria, Belgium, Canada, China, France, Germany, Indonesia, India, Italy, Japan, Malaysia, the Netherlands, Singapore, South Korea, Spain, Sweden, Switzerland, Thailand, the United Kingdom, and the United States.

${ }^{11}$ The empirical model, without the interaction term between changes in the home-country prudential measures and bank-level variables, is also estimated and results are reported in appendix 2 of Ho, Wong, and Tan (2016).
} 


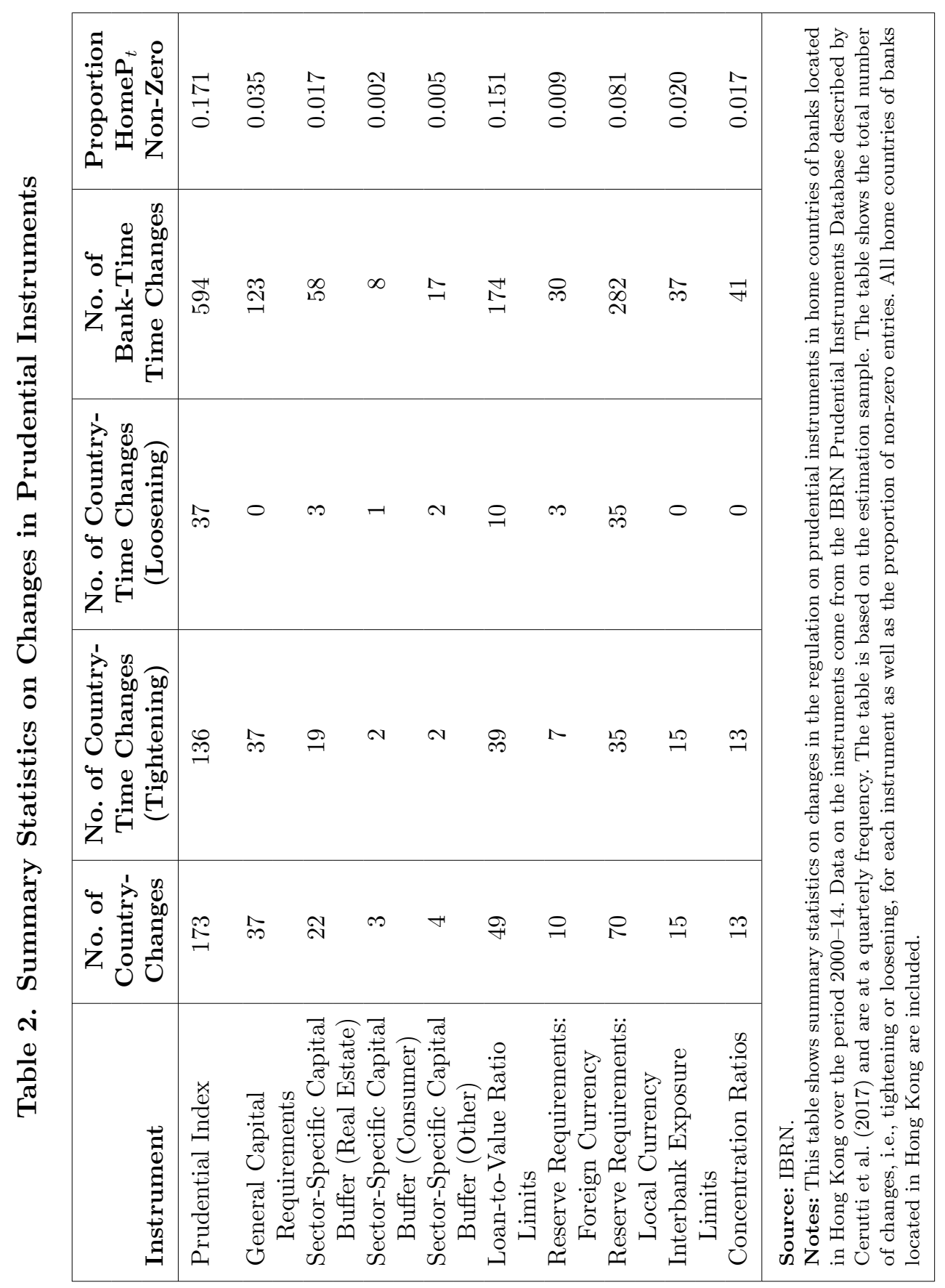


where $\Delta Y_{b, j, t}$ is the log change in total lending of the foreign bank $b$ in Hong Kong whose parent bank is headquartered in country $j$ at time $t\left(\Delta\right.$ Loans $\left._{b, j, t}\right) . X_{b, j, t-1}$ is a vector of bank-level variables $\left\{\right.$ IlliquidAssetsRatio $_{b, j, t-1}$, CoreDeposits $_{b, j, t-1}$, Tier 1Ratio $_{b, j-1-1}$, LogRealAssets $_{b, j, t-1}$, NetDueTo $\left.o_{b, j, t-1}\right\}$, which captures the degree to which a foreign bank $b$ is exposed to changes in regulation in the home country $j$ through ex ante balance sheet composition and market access, while NetDueTo $o_{b, j, t-1}$ captures the FBA's dependence on net intragroup funding. $Z_{j, t}$ represents the business and financial cycle variables for country $j$, as compiled by the Bank for International Settlements (BIS) 12 The business cycle is defined as the output gap measured as a percentage of potential output, which is estimated by a Hodrick-Prescott filter on log real GDP, while the financial cycle is measured by the credit-to-GDP ratio gap. The prudential policy changes are captured by the variable HomeP.

The baseline model includes bank and time fixed effects, $f_{b}$ and $f_{t}$ respectively, with the latter capturing changes in loan demand conditions and host-country prudential measures that are common across banks in Hong Kong 13 Since the regression model includes $f_{b}$ and $f_{t}$, the estimated $\beta\left(=\beta_{1}+\beta_{2}+\beta_{3}\right)$ reflects the importance of cross-sectional differences in balance sheet characteristics on the response of $\Delta Y_{b, j, t}$ to changes in HomeP.

Table 3 reports the estimation result for equation (1) by types of prudential policy instruments. For brevity, the reported coefficients on the interaction terms (i.e., $X_{b, j, t-1} *$ HomeP) are the sum of the contemporaneous term and two lags (i.e., $\beta=\beta_{1}+\beta_{2}+\beta_{3}$ ). The interaction terms show how banks with different balance sheet characteristics adjust their FBA total lending in Hong Kong in response to regulatory changes imposed in the home country.

\footnotetext{
${ }^{12}$ For details on business cycle variables, see Drehmann, Borio, and Tsatsaronis (2011). For financial cycle variables, see BIS (2014).

${ }^{13}$ While the time-effect dummies capture the economy-wide loan demand that is common across banks in Hong Kong, these dummies may not fully absorb the country-specific component of the loan demand. Specifically, to the extent that the FBA's borrowers in Hong Kong have some ties to the home country of the foreign banks, it is possible that the country-specific component of the loan demand may be related to home-country regulatory changes. Therefore, business and financial cycle variables of the home countries of the foreign banks are included in the model to account for the country-specific component of the loan demand.
} 


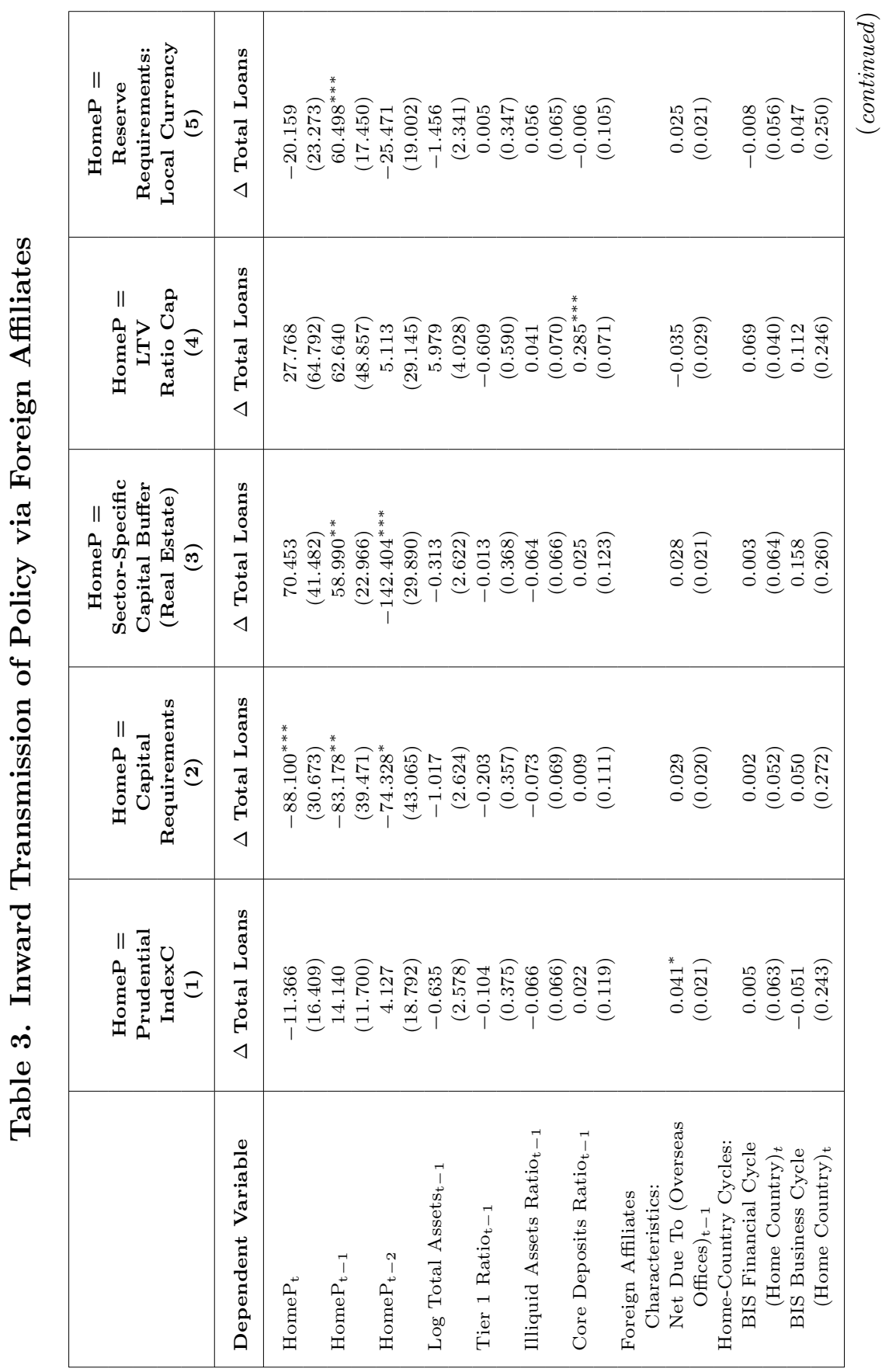




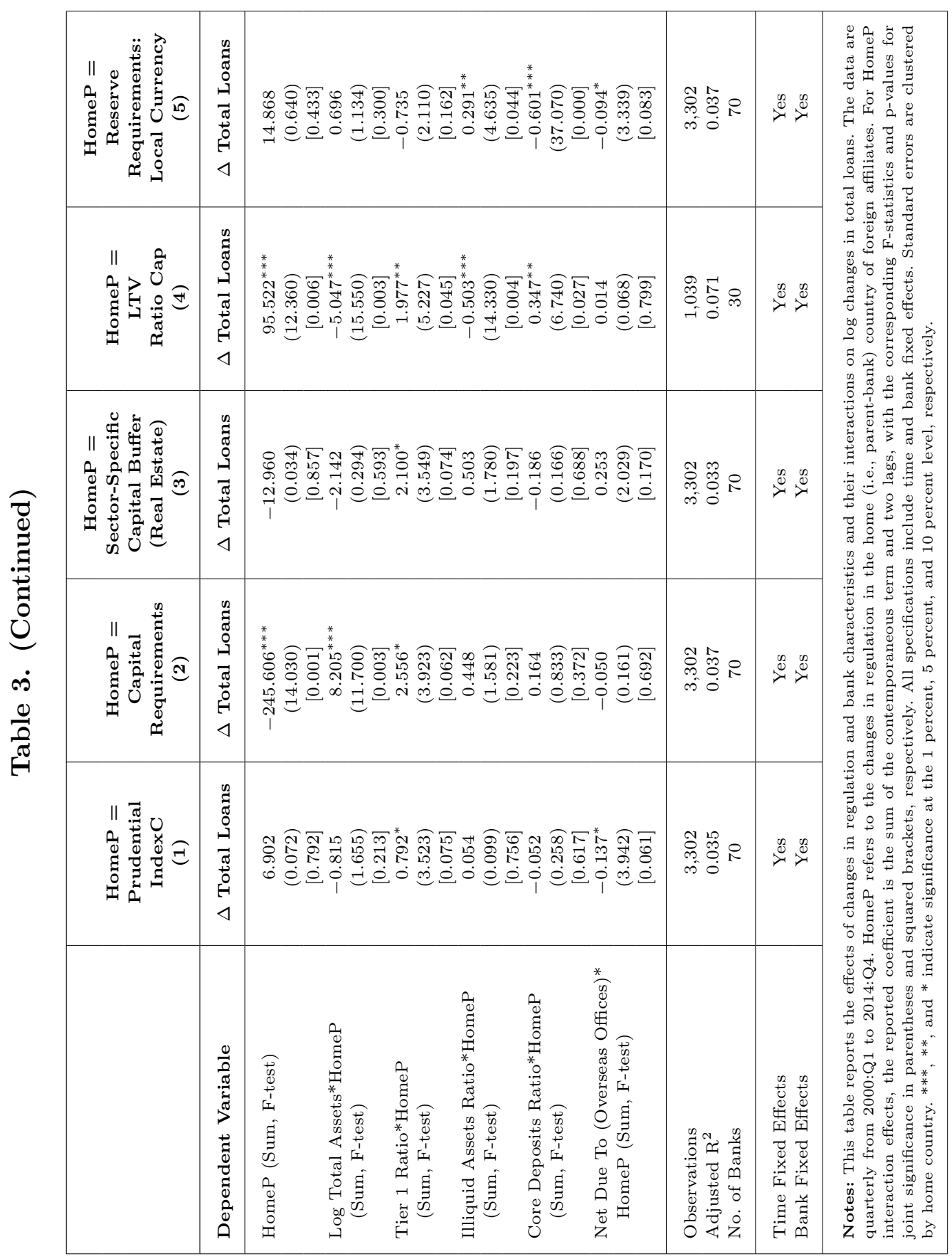


We focus on the bottom panel of table 3 , where the estimation results for the interaction terms between HomeP and the selected balance sheet characteristics are presented. The estimation results show that bank balance sheet characteristics do affect the inward spillover effects of HomeP. Specifically, we find that in response to tighter capital requirements (both for CapitalReq and SSCB), a bank with a higher tier 1 ratio tends to sustain higher loan growth of its affiliates in Hong Kong than that of other FBAs in Hong Kong (see row Tier1Ratio ${ }^{*}$ HomeP) 14 This may reflect that tighter capital requirements may be less likely to produce a binding constraint on well-capitalized banks, and therefore their affiliates can register higher loan growth than the FBAs of less capitalized banks.

However, the significance of tier 1 ratio as a determinant of the inward spillover effects does not carry over for liquidity-related measures (see columns 5 and 6 ). Instead, we find that the liability structure of banks matters more in determining cross-sectional differences in lending by FBAs in Hong Kong. For RRLocal, we find that banks with a higher deposits ratio tend to reduce lending growth of their FBAs in Hong Kong by more than their peers (see row CoreDepositsRatio ${ }^{*}$ HomeP in column 5). This probably reflects the notion that tighter reserve requirements tend to reduce the lending capacity more for banks with a higher deposits ratio.

The reliance on internal funding, as proxied by NetDueTo, is another important factor in determining the extent of the inward spillover effects for RRLocal (see row NetDueTo*HomeP for column 5). Specifically, FBAs that rely more on net intragroup funding (i.e., a high positive value of NetDueTo) are estimated to have lower loan growth than their peers in Hong Kong in response to a tighter RRLocal, suggesting that a bank's internal capital market is an important channel in transmitting inward spillover effects of liquidity-related HomeP internationally.

Finally, for LTVCap (see column 4), our findings suggest that both banks' capital adequacy and liquidity are important factors

\footnotetext{
${ }^{14}$ To reveal whether differences in loan responses are driven by home-country effects, we reestimate the baseline model and replace the bank fixed effects with home-country fixed effects as a robustness check. The results are broadly in line with those reported in table 3 , suggesting that the significant differences in loan response arising from cross-sectional differences in a bank's capital adequacy position are not driven by home-specific effects. The estimation results are presented in appendix 3 of Ho, Wong, and Tan (2016).
} 
affecting inward spillover effects. This result shows that banks with stronger balance sheet conditions (i.e., higher tier 1 ratio, lower illiquid assets ratio, and higher core deposits ratio) tend to have higher loan growth of affiliates in Hong Kong than their counterparts.

The above findings suggest that cross-sectional differences in the balance sheet composition of banks influence the international transmission of prudential policy 15 To reveal whether the findings in table 3 are robust to alternative specifications, we reestimate the baseline model without bank fixed effects and find that the results are similar (table 4) 16 In table 4 , the $\beta$ coefficients capture absolute and cross-sectional differences in balance sheet composition.

In the final part of the baseline analysis, we conduct a simple exercise to assess the economic significance of differences in loan responses arising from cross-sectional differences in balance sheet characteristics based on the estimation results reported in table 3 . First, we consider tier 1 capital ratio. The coefficient on the interaction between CapitalReq and tier 1 capital ratio (2.556, from the second column of the bottom panel of table 3 ) and the standard deviation of tier 1 ratio (2.74, percent from table 1 ) implies that an FBA moving its tier 1 ratio up by one standard deviation will increase total loan growth by 7.0 percent relative to its initial position. We repeat this exercise for all significant balance sheet characteristics for the four types of prudential policies and report the results in table 5, panel A. The economic magnitude of the differences in loan responses (in absolute terms) ranges from 3 percent to 12.3 percent 17 In table 5 , panel $\mathrm{B}$, we present the economic significance of differences in loan responses by increasing the balance sheet variables from a position at the 25 th percentile to the 75 th percentile. These results suggest that the lending growth of FBAs in Hong Kong is quite sensitive to home prudential policies through the balance sheet of their banking organization.

\footnotetext{
${ }^{15}$ Recall that the baseline regression model includes both bank and time fixed effects. The coefficient on the interaction terms $\beta$ therefore measures how the structure of banks' balance sheets affects the response of an FBA's lending to tighter prudential policies in the home country.

${ }^{16}$ The adjusted $\mathrm{R}^{2}$ remain broadly similar after excluding bank fixed effects (i.e., table 4), suggesting that bank time-invariant fixed effects only have limited explanatory power for log changes in total loans.

${ }^{17}$ The former is for the difference in loan response to tighter reserve requirements due to NetDueTo, while the latter is for the difference in loan response to tighter reserve requirements due to CoreDepositsRatio.
} 


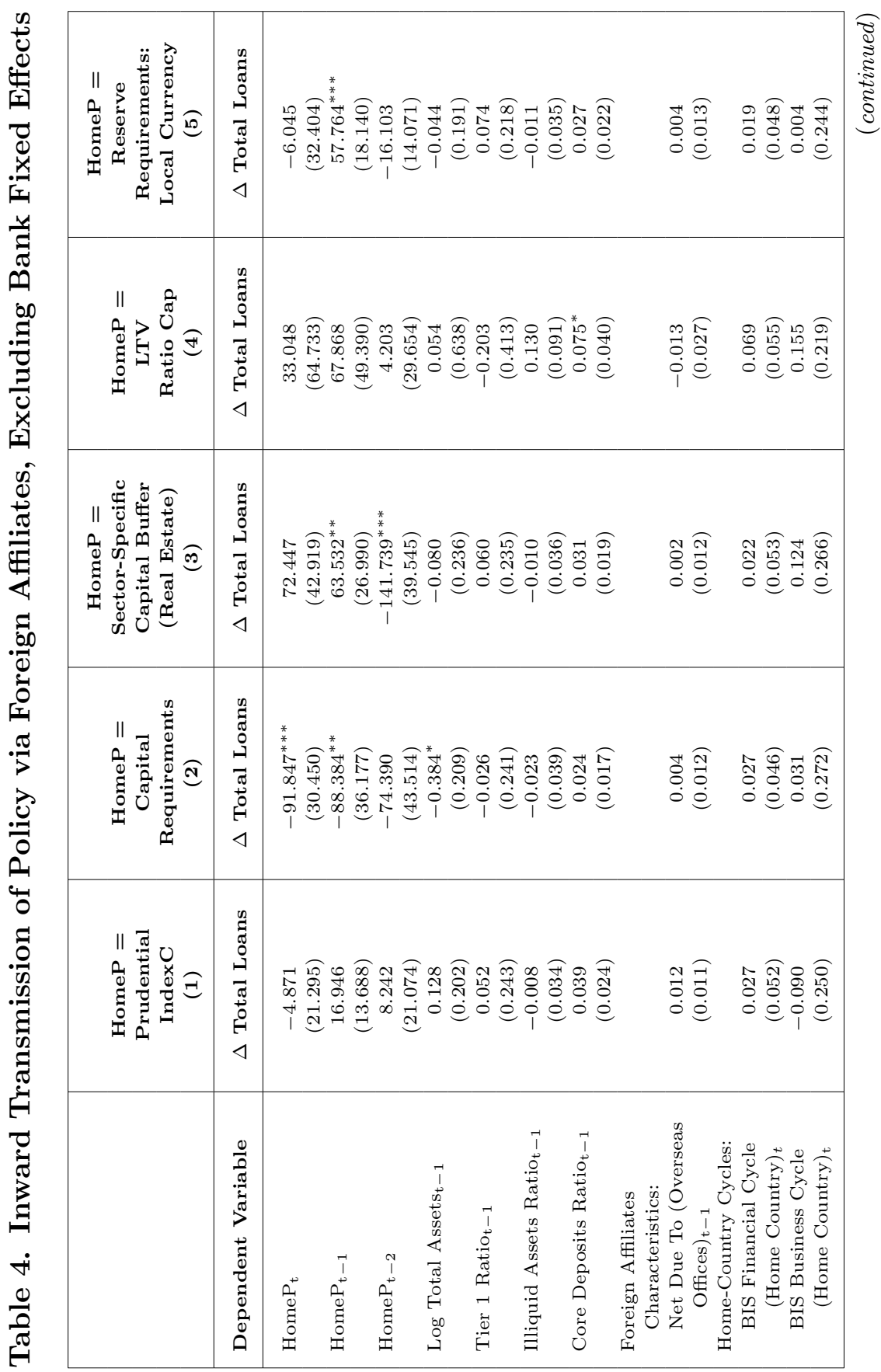




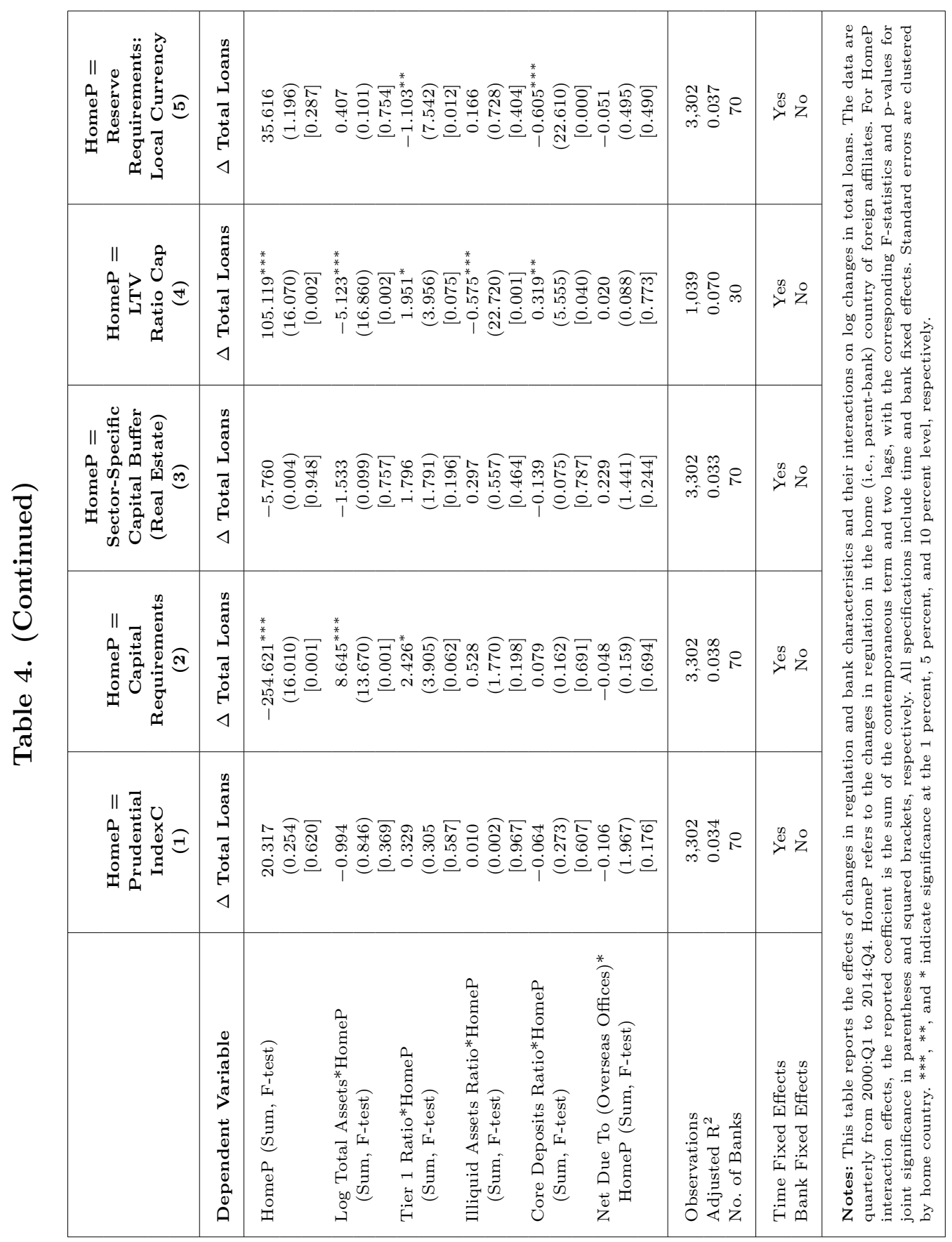




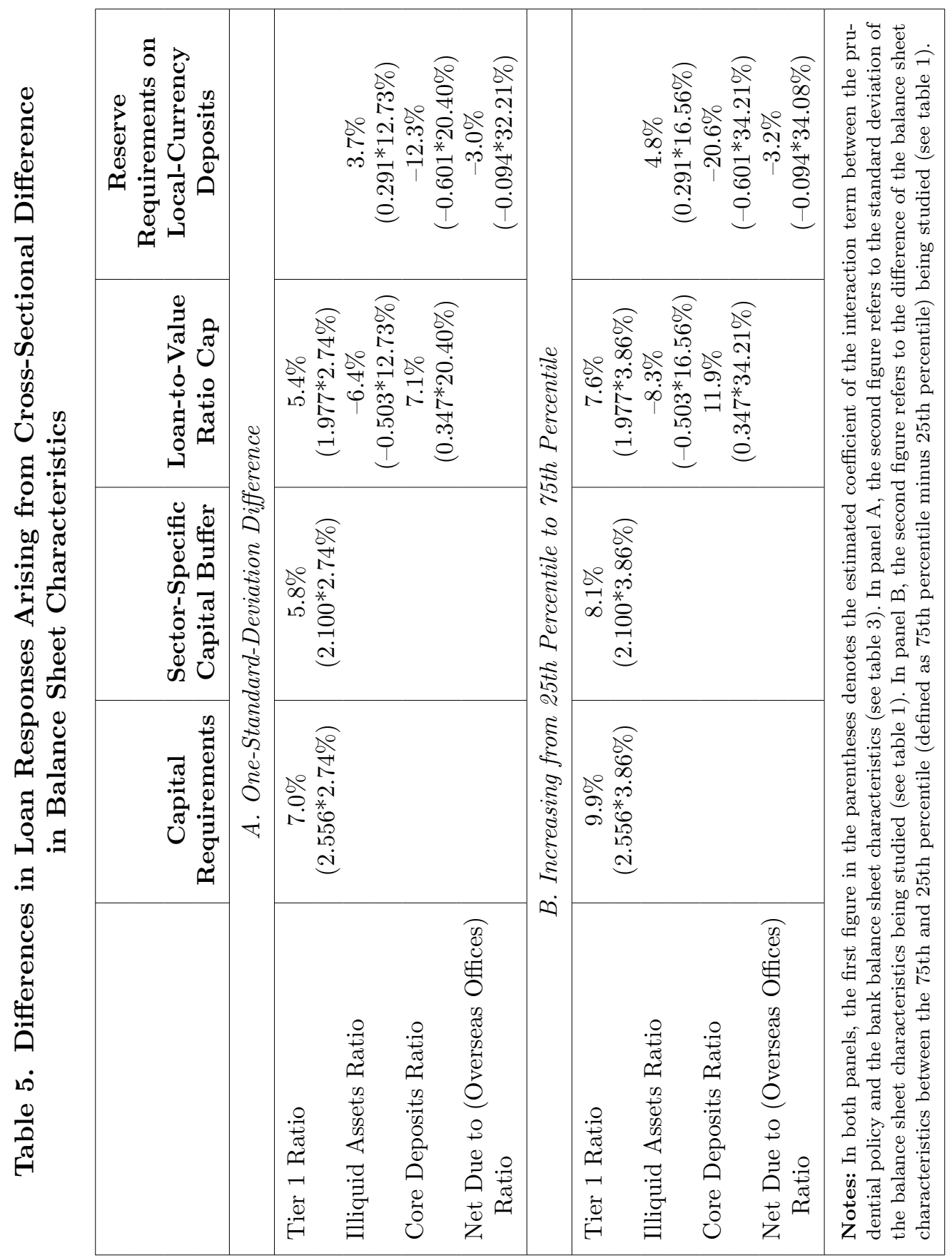




\subsection{Economic Magnitude and the Pattern of Inward Spillover Effects}

The significant impact of balance sheet characteristics on the loan responses of FBAs to home prudential policies, as identified in the previous section, together with the heterogeneous balance sheet structure among international banks poses an important question. What is the degree of diversity in the inward spillover effects among FBAs both in terms of the direction and size of their loan responses? Answering this question may help policymakers gauge the potential impact of inward spillover effects on loan supply in their banking sectors. To shed light on this issue, we analyze the distribution of loan responses among FBAs to different prudential measures. Our core interest is on whether FBAs would generally adjust their loans in the same direction in response to tighter home prudential policy. We are also interested in assessing the aggregate impact of FBAs' loan responses on total lending in the banking sector. All estimates in this section are based on the estimation results reported in table 4 (i.e., without bank fixed effects), as they capture both absolute and cross-sectional differences in loan responses.

Figure 2 presents the distribution of the estimated marginal effect of tighter home prudential policies on total loans of FBAs based on our estimation results. Recall that from equation (1), the marginal effect on the log change of total loans over quarter $t$, due to homecountry regulatory changes over the three quarters, for each FBA can be obtained by summing the partial derivative of $\Delta Y_{b, j, t}$ with respect to contemporaneous HomeP and the two lags of HomeP, which is equal to $\left(\alpha_{1}+\alpha_{2}+\alpha_{3}\right)+\left(\beta_{1}+\beta_{2}+\beta_{3}\right) X_{b, j, t-1}$. Taking the sample mean of balance sheet characteristics of bank $b$ (i.e., $\bar{X}_{b, j}$ ) together with the estimated coefficients $\hat{\alpha}$ and $\hat{\beta}$ gives an average estimated marginal effect of HomeP for bank $b$. To reveal a fuller picture, figure 2 shows the estimated impact of contemporaneous and three-quarter cumulative changes of home-country prudential measures 18 The bars show the average loan responses by quantile (which

\footnotetext{
${ }^{18}$ The estimated contemporaneous impact of HomeP is calculated by the partial derivative of $\Delta Y_{b, j, t}$ with respect to the contemporaneous HomeP at time $t$, which is equal to $\hat{\alpha_{1}}+\hat{\beta}_{1} \bar{X}_{b, j}$.
} 


\section{Figure 2. Distributions of Inward Spillover Effects on Total Loans (by type of instrument)}
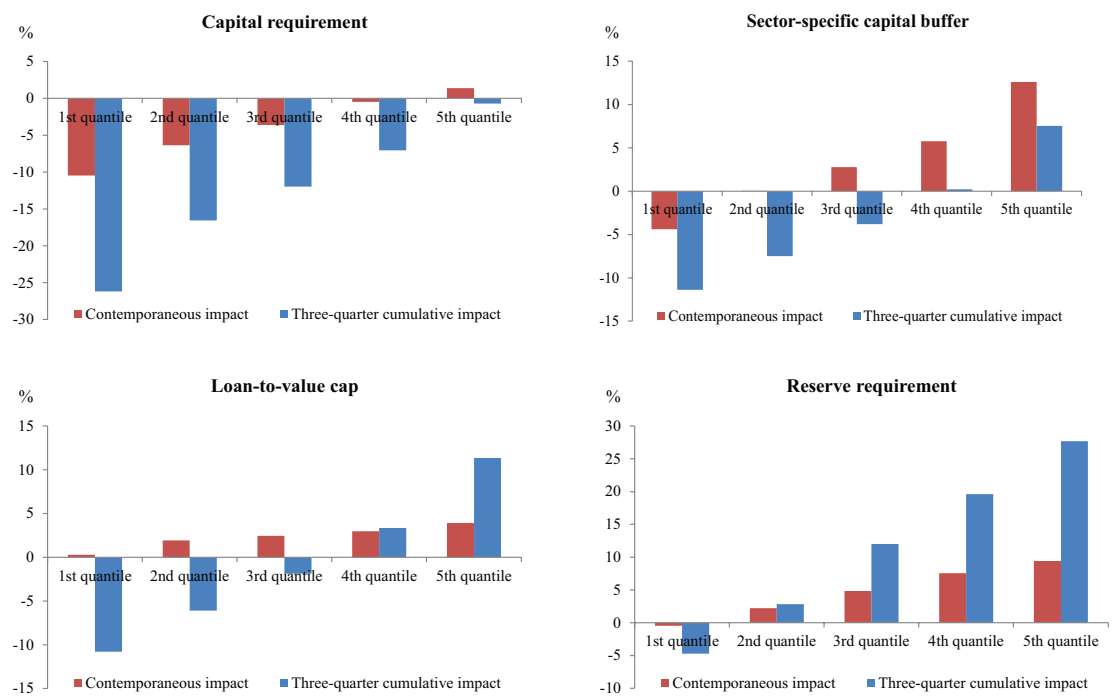

are sorted by the estimated loan responses). Among the four prudential measures considered, only the overall capital requirements are estimated to generate a clear pattern of spillover effects: most FBAs in the sample reduce their loans in response to tighter overall capital requirements in the home country. One plausible explanation is that the overall capital requirements are a consolidated and non-sectoral specific measure such that the loan response of FBAs is consistent with the expected loan response of the whole banking organization (i.e., reducing loans). Affected banks may not have much room to mitigate the regulatory impact through rebalancing loan portfolios among entities within the banking organization (i.e., a "waterbed effect") 19 Consistent with the above conjecture, we find a mixed

\footnotetext{
${ }^{19}$ For $R R L$ Local, the differences in loan response among FBAs may be attributable to the fact that the scope of application for reserve requirements varies across countries. For example, European bank branches located outside European Union member states are not subject to home reserve requirements. In this regard, banks may respond differently to the same tightening stance depending on whether the foreign banks in Hong Kong are subject to the reserve requirements imposed in their respective home country.
} 
pattern of loan responses among FBAs to sector-specific prudential measures. Broadly speaking, our results suggest that half of FBAs in Hong Kong increase their loans in Hong Kong in response to a tighter $S S C B$ and LTVCap in the home country, and the remaining half of FBAs reduce their loans.

One hypothesis that may account for the mixed pattern of loan responses to sector-specific prudential measures is that banks mitigate the regulatory impact by rebalancing their loans portfolio between and/or within bank affiliates. To test this hypothesis, we repeat our estimation exercise on log changes in mortgage loans, corporate loans, and consumer loans, respectively. The estimation results are reported in table 6 . Based on the estimation results, we estimate the marginal impact on FBAs' mortgage, corporate, and consumer loan growth to tighter SSCB and LTVCap. The distribution of loan responses among FBAs is presented in figure 3, which generally supports the view that affected banks may try to partially offset the regulatory impact by redistributing their loan portfolio toward exposures that are not subject to or outside the scope of tighter prudential policies. Specifically, for $S S C B$, most of the affected banks are estimated to contract their mortgage and consumer loans while expanding their corporate loans. Likewise, it is found that most affected banks expand their mortgage loans in Hong Kong in response to lower LTV caps imposed in the home country, probably reflecting the fact that banks have strong incentives to maintain their portfolio mix by increasing mortgage loans in overseas markets 20

Finally, we assess the possible impact of inward spillover effects on the banking sector, by estimating the aggregate loan response among FBAs for different prudential policies. Table 7 reports both the aggregate marginal impacts of contemporaneous and threequarter cumulative changes in home-country prudential measures on total loans of affected FBAs (as a percentage of the banking sector's loans). To calculate the aggregate marginal impact of HomeP, we compute the estimated change in a bank's loans by multiplying a

\footnotetext{
${ }^{20}$ The directional change in corporate and consumer loans is less clear in the case of $L T V C a p$, which may partly reflect the possibility that some banks expand their mortgage loans at the expense of corporate and consumer loans.
} 


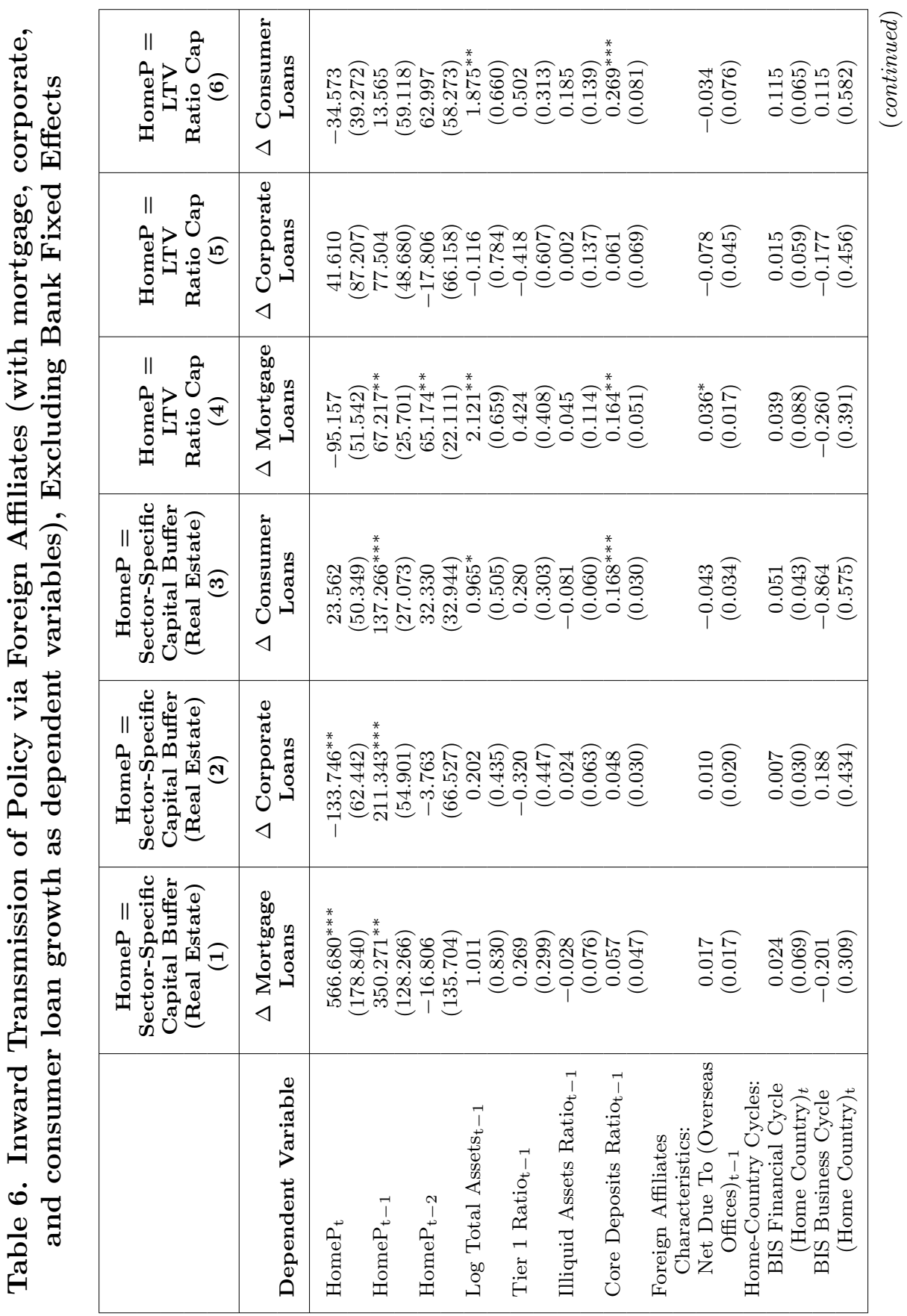




\begin{tabular}{|c|c|c|c|c|c|}
\hline 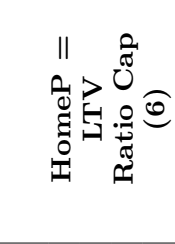 & 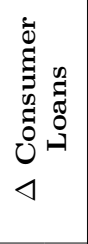 & 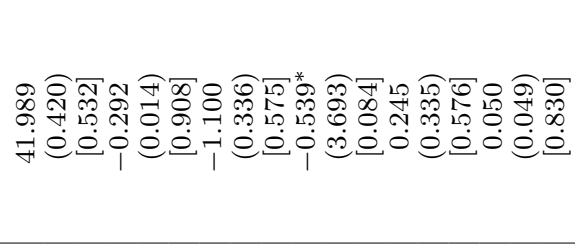 & 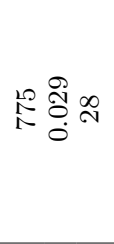 & $\underbrace{\infty}_{0 \rightarrow \infty}$ & 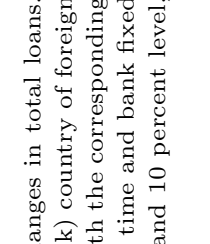 \\
\hline 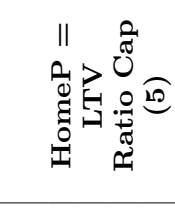 & 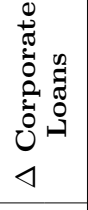 & 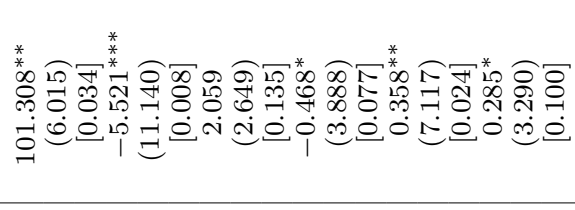 & 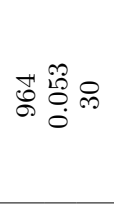 & 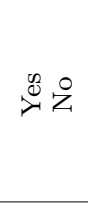 & 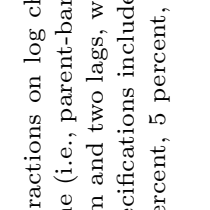 \\
\hline 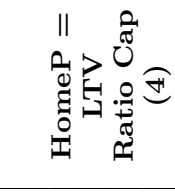 & 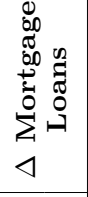 & 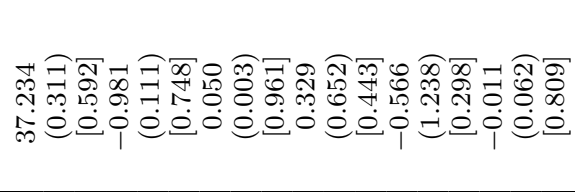 & 品 & 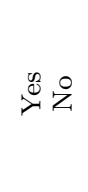 & 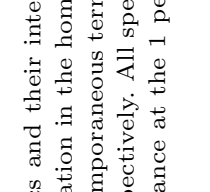 \\
\hline 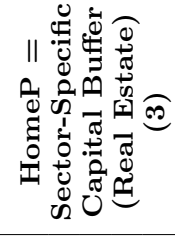 & 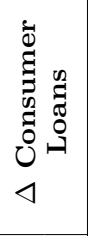 & 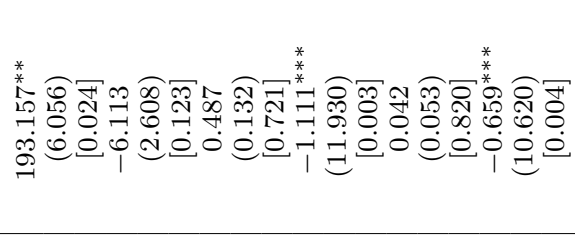 & 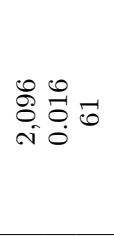 & 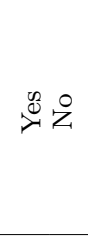 & 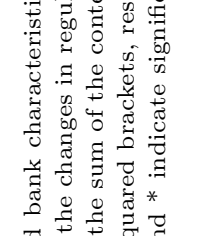 \\
\hline 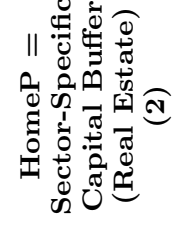 & 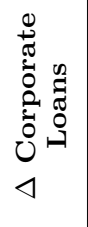 & 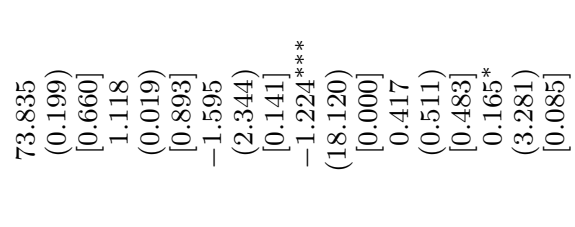 & 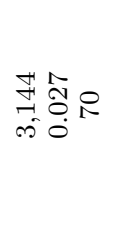 & 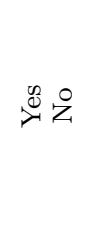 & 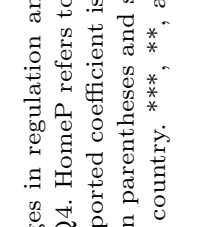 \\
\hline 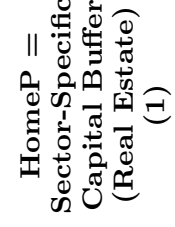 & 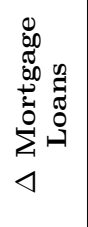 & 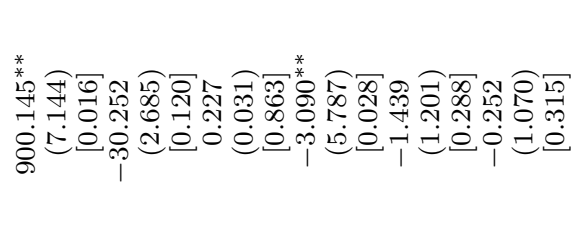 & 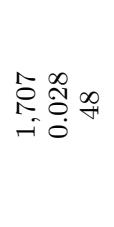 & 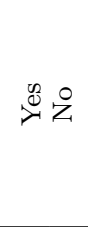 & 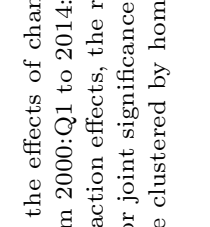 \\
\hline & 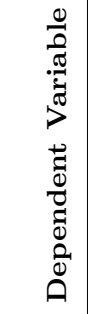 & 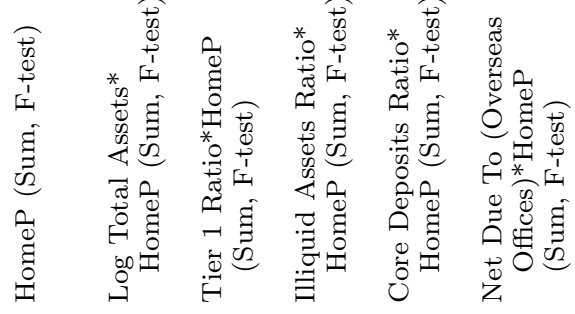 & 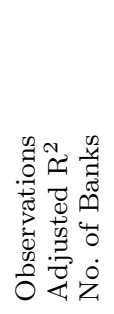 & 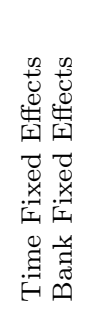 & 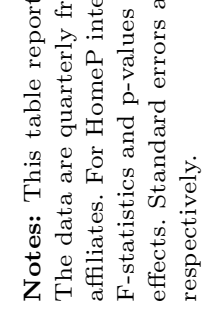 \\
\hline
\end{tabular}


Figure 3. Distributions of Inward Spillover Effects on Mortgage, Corporate, and Consumer Loans to Tighter Sector-Specific Measures (SSCB and LTVCap)
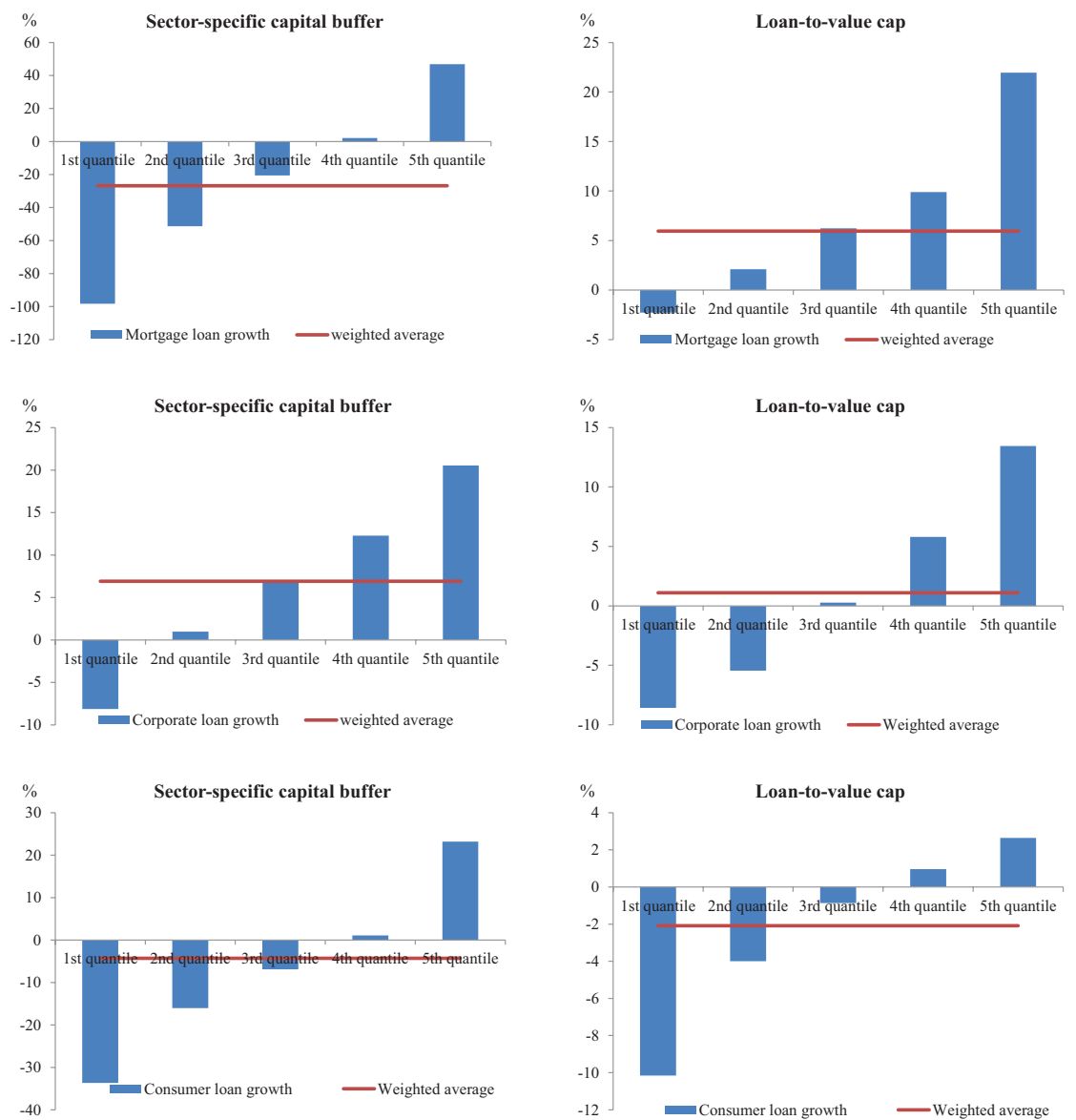

bank's estimated marginal effect of HomeP by its total loans at the end of 2014. We then sum across the estimated change in loans of the affected FBAs and divide by the total amount of loans in the Hong Kong banking sector at the end of 2014. In computing the aggregate marginal impact of a prudential measure, we further assume that all countries which have adjusted prudential measures during the 


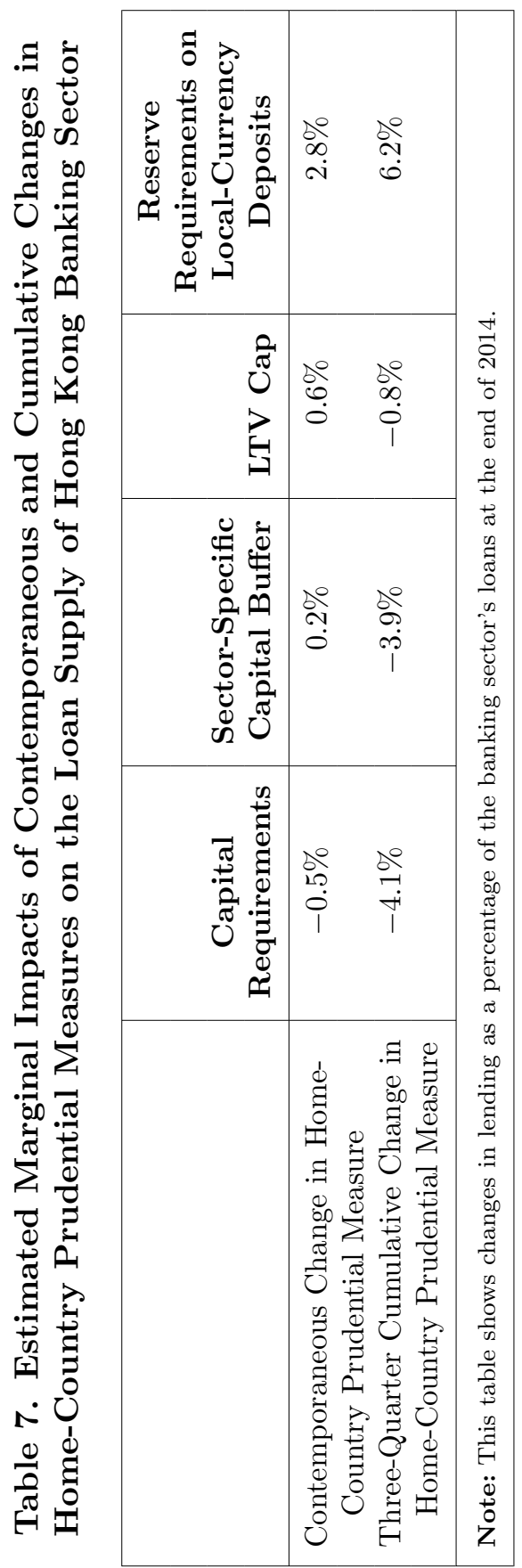


estimation period simultaneously tighten the policy 21 The size of the spillover effects is larger for the overall capital requirements and the reserve requirements on local-currency deposits. The impact of three-quarter cumulative changes in home-country prudential measures is equivalent to a 4.1 percent decline in total loans in Hong Kong for CapitalReq and a 6.2 percent increase in total loans for RRLocal. Conversely, the impact of sector-specific prudential measures is relatively small, which may be attributable to a significant portfolio rebalancing effect within FBAs.

\section{Concluding Remarks}

Using a confidential data set of FBAs in Hong Kong, our study finds evidence of an international transmission of prudential policy through banks' balance sheets. The set of balance sheet factors that influence the spillover transmission is found to vary according to the nature of the prudential measure (i.e., capital or liquidity related) considered. Specifically, a bank's tier 1 capital ratio affects the loan response of its FBAs in Hong Kong to tighter capital requirements in the home country, while a bank's core deposit share and its reliance on internal funding affects its loan response to tighter liquidity requirements. One implication is that, from a host supervisor's perspective, understanding the balance sheet structure of the banking organization of an FBA is important in assessing the international transmission of prudential policy.

From a host country's perspective, the spillover effects from prudential measures abroad on loan supply of the domestic banking sector may be the most important policy question. Our empirical findings show that the size of the spillover effects arising from changes in the overall capital requirements and reserve requirements is larger than the size of those for sector-specific measures. The relatively smaller spillover effects for sector-specific prudential measures can be partly explained by a significant portfolio rebalancing effect across and within affiliates of international banks, thus making the net impact on the host country less clear.

\footnotetext{
${ }^{21}$ This assumption provides a hypothetical scenario which is similar to an upper-bound estimate of the aggregate spillover effects on the Hong Kong banking sector.
} 


\section{References}

Bank for International Settlements. 2014. "Debt and the Financial Cycle: Domestic and Global." In 84th Annual Report, 65-84 (chapter IV). Basel, Switzerland: Bank for International Settlements.

Buch, C. M., and L. S. Goldberg. 2014. "International Banking and Liquidity Risk Transmission: Lessons from Across Countries." IMF Economic Review 63 (3): 377-410.

- 2017. "Cross-Border Prudential Policy Spillovers: How Much? How Important? Evidence from the International Banking Research Network." International Journal of Central Banking 13 (S1).

Cerutti, E., R. Correa, E. Fiorentino, and E. Segalla. 2017. "Changes in Prudential Policy Instruments-A New Cross-Country Database." International Journal of Central Banking 13 (S1).

Cetorelli, N., and L. S. Goldberg. 2012a. "Follow the Money: Quantifying Domestic Effects of Foreign Bank Shocks in the Great Recession." American Economic Review 102 (3): 213-18.

2012b. "Liquidity Management of U.S. Global Banks: Internal Capital Markets in the Great Recession." Journal of International Economics 88 (2): 299-311.

Cornett, M. M., J. J. McNutt, P. E. Strahan, and H. Tehranian. 2011. "Liquidity Risk Management and Credit Supply in the Financial Crisis." Journal of Financial Economics 101 (2): 297312.

Drehmann, M., C. Borio, and K. Tsatsaronis. 2011. "Anchoring Countercyclical Capital Buffers: The Role of Credit Aggregates." International Journal of Central Banking 7 (4): 189-240.

Ho, K., E. Wong, and E. Tan. 2016. "International Banking and Cross-border Effects of Regulation: Lessons from Hong Kong." HKIMR Working Paper No. 12/2016. 